\title{
Pornography in Small Places and Other Spaces
}

\section{Katrien Jacobs}

\begin{abstract}
This article investigates pornography's free speech at a time when commercial pornography has flooded the Internet and pockets of erotic activism are budding alongside the porn boom. Pornography moving freely across borders is foremost a capitalist vision, but online correspondents also construct non-conformist networks around Internet commodities and partake in gift economies. Revisiting Foucault's notion of space as "heterotopia," networked pornographic communication is shown to permeate physical places and other spaces. Online correspondents cultivate attachments to porn in "small" places and spaces other than the ones they routinely inhabit. Networked pornographic agency also materializes sexuality beyond the confines of dominant consumer industries. Besides the fact that dominant industries expand their markets and diversify products, sex communities emerge alongside these markets and play a vital role in negotiating sexuality. The article shows how the Internet's decentralized distribution mechanisms and diversified free-thinking have entered the realm of online porn and sexuality. Developing a theoretical notion of space as other spaces, the article unfolds the object of pornography as exuberant, dispersed in bodies and cultures, yet forcefully regulated by global corporations and nation-state governments.
\end{abstract}

\section{Keywords}

Internet pornography, censorship, globalization, heterotopia. 


\section{Pornography in Small Places and Other Spaces}

\section{Internet Porn and Censorship}

Internet pornography is increasingly produced and consumed as a transnational commodity-culture by net users who live in a variety of cultures and places. The primary commercial agents of porn today are product distributors who work with porn companies to produce videos and make web sites for global distribution. For instance, American hotel chains such as Marriot and Westin are garnering easy benefits from the porn boom. In return for offering in-room x-rated movies (distributed by Lodgenet and On Command) these hotel chains receive a profit percentage. Next, there are cable and sattelite companies such as ATET and General Motors (DirectTV) who channel porn into millions of homes and take a huge share of the profit or money spent by consumers. An independently owned business such as Danni's Harddrive, a popular softcore porn site owned by former porn star Danni Ashe, now employs 45 people and made a profit of 6.5 million in 2001. Bill Asher, president of Vivid Entertainment Group, one of the largest adult-video production companies in the United States, describes the porn industry's wet dream:

We really have only scratched the surface right now. If you look at how many television homes there are in this world, or will there be, how many total homes there are, versus how many can get adult, we're still a very, very small percentage. The Internet has really obviously increased that, but again, the Internet is not the true experience of adult (...) Right now domestically in this industry it is $\$ 4$ billion to $\$ 10$ billion. Where would it be worldwide 10 years from now ${ }^{1}$

The Internet is indeed becoming the ultimate experience for adult entertainment and creating a unique space for corporate and independent pornographers, professionals and amateurs, to produce, distribute and consume products. Frederick's Lane study of porn 
enterpreneurism, Obscene Profits. The Enterpreneurs of Pornography in the Cyber Age, rightly takes into account the new role of independent women as enterpreneurs. As he writes:

The ability of women to participate in the pornography industry without the intervention of a (typically male) magazine editor or video producers has profound implications for the industry as a whole (...) The Internet has the effect of suddenly making any woman who chooses to set up her own nude Web site the head of her own Playboy-like channel or publisher of her own Penthouse-like magazine. Admittedly, the established players in the pornography industry have enormous technical, financial, and editorial resources (...) But amateur Web site operators have their own enormous draw: the very realness of the images they offer and the inherent voyeurism of looking at them (Lane, 2000: 113).

Megastars such as Danni Ashe and small-scale entrepreneurs have started to build web sites in order to distribute their works and create a different environment for their consumers.

In an attempt to monitor web-based porn exchanges, federal Governments in countries as diverse as the USA, Australia, the UK, and France, have started to issue stringent censorship laws. The fear that the Internet kindles the growth of porn that is violent, harmful and exploitative to children, produces haphazard policy-making by legislators and corporations in their desire to control electronic information. An example would be the UK-based action Operation Ore, a piece of legislation that currently enables the police to monitor and arrest web users engaged in acts of "child pornography" without investigating the social or ethical codes of conduct developed by online correspondents.

John Perry Barlow of the Electronic Frontier Foundation (EFF) in "Censorhip 2000" predicts a large networked anti-porn effort in the USA and Europe, as nation-states and international organs such as the G8 (Group of Eight Industrial Nations) are collaborating with ISP's (Internet Service Providers) to act as legislators of the Internet (Barlow, 2000). Internet Service Providers in several countries are now forced by law to report illegal 
traffic to the police. The UK-based Internet Watch Foundation, made up of Internet industries, government and consumer representatives, encourages web users themselves to report on illegal traffic. The Internet Watch Foundation prides itself on encouraging citizens to interact with policies and become autonomous governing bodies using a centralized and user-friendly web site. The foundation works in partnership with ISPs, Telcos, Mobile Operators, Software Providers, Police and Government. The goal is to minimize the availability of illegal Internet content, particularly child abuse images. As they write: "Our Internet Hotline can deal with reports of potentially illegal Internet content, such as websites, newsgroups and online groups that contain images of child abuse anywhere in the world; adult material that potentially breaches the Obscene Publications Act in the UK; or criminally racist material in the UK." Self-government and surveillance of citizens are presented as civil duties that lead to results, as the foundations proudly reports: “2450 notifications sent to the police in 2001."

Barlow believes that such alliances between nation-state governments and Internet industries may easily result in the political suppression of marginal groups, as it creates a tide of intolerance: "Within narrower contexts, suppressing the expression of gays, women, heretics, traitors, and troublemakers is politically popular"(Barlow, 2000). Government bodies such as the Internet Watch Foundation may lead to a moral mainstreaming of the body politic, rather than an understanding of decentralized sexual communities. An example would be the recent censorship and removal of online sexual communities by commercial portals. This has been particularly the case for commercial host portals such as Egroups, Yahoo, Excite, and Visto who have disabled legal adult websites for gay communities where materials deemed to be "obscene", such as pictures of urinating boys, were exchanged. Since those sites were hosted by corporate host portals as free services, the portals were "free" to set any terms of service (TOS) they chose. For instance, the Visto.com TOS reads: "We reserve the right to terminate any subscriber, without disclosure of specific reason for said termination, at our own discretion, if we deem that such termination is in the best interest of Visto Corp". ${ }^{3}$ It is important to note that such control on adult sites is indeed damaging the educational and social functions they perform. Some of the moderators of censored sites have 
maintained extensive discussions about nudity between children and non-parental adults in order to resist a generalized representation of this taboo area of sexuality. ${ }^{4}$

While depictions of nude minors within gay and lesbian networks spur moral outrage in the USA, these depictions may also be tolerated in other cultures such as Japan. Mark McLelland (2000) notes, for instance, that scatological references may appear obscene to western audiences, but they are more commonplace in Japanese media. Discussing the website Saki's Room and illustrations with urination and masturbation themes, McLelland suggests that "the most troubling illustration for a western viewer involve scenes depicting interplay between male minors" (p.283-284). Mc Lelland's research show that areas of censorship and taboo in one particular culture are often ignored in another culture.

The future of global porn, as Barlow points out, may indeed be chilling censorship measures and scenes of conflict between webusers and ISP's who are forced by local governments to apply the most stringent measures of censorship legislation. An example of reactionary "small place" legislation would the Western Australian Censorship Act of 1996, an ad-hoc state law intended to forego the mechanisms of the Australian Federal Government. The Western Australian Censorship Act came about to protect local state territory from the influx of hard-core or 'edgy' pornographic materials. Western Australian citizens are asked to report on objectionable articles transfered into Western Australian territory through online communication. Moreover, the act states that a member of the police force, or an authorized person, can without warrant enter the place where "objectionable" articles are exhibited. ${ }^{5}$

The Western Australian Censorship Act has been followed globally by legislation that reinforces borders and monitors the influx of Internet materials that could be intrusive and damaging to 'local' citizens, particularly children. For example, South Australia's Internet Censorship Bill of 2002 criminalizes any content "unsuitable for children online" even if the content is clearly targeted towards adult groups. This bill is very intrusive to adult industries and free speech practices, as it enables the police to evaluate and arrest individuals who post information deemed offensive to children. In Massachusetts, USA, a similar bill has passed that makes it illegal to upload or 
download images containing the nudity of a person under 18, even the images are not considered "pornographic".

In May 2002, the USA Federal Court struck down the Child Online Protection Act (COPA) a bill that argues that the Internet automatically exposes children to pornographic materials. As stated by Senator N. Haynes: "If adults and children are mutually given unfettered access to adult and obscene materials via the Internet, a child's computer is essentially converted into an adult bookstore"(Supreme Court Debates, Feb. 2002: 61). The debate between U.S. Attorney General John Ashcroft and the ACLU (American Civil Liberties Union) questions if community standards of decency can be transferred from place to place. Whereas the ACLU argues that a federal censorship law for the Internet would result in applying the most conservative community standards to the entire nation, Ashcroft replies that community standards for minors are different from adults and likely to be "reasonably constant" throughout the nation. Even if different cultures have different ways of digesting pornographic materials, there is no difference in how Internet porn affects children globally. The most compelling arguments against Ashcroft have come from researchers within Society for the Scientific Study of Sexuality and the Institute for the Scientific Study of Sexuality who have found that there is no sufficient evidence that children are harmed by exposure to sexually explicit words or images (Supreme Court Debates, Feb 2002: 60). Moreover, these researchers have also found that the category of 'minors' (18 years or less in the USA) is too broad upon which to apply a measure of child psychology.

In response to the 1998 Child Internet Protection Act (CIPA), an act that requires public libraries to filter their computers if they want to retain federal funding, Judith Krug of the American Library Association finds that most current filtering software is still flawed. She adds that "it would be better to educate children and teenagers about the various uses of the Internet rather than rely on software to help them navigate"(Loviglio, 2002). In her controversial book Harmful to Minors: The Perils of Protecting Children from Sex, Judith Levine argues that the "harfmul to minors" obscenity standard, operational in the USA since 1968, is currently being revamped by government to phase out sexuality debates rather than promote tolerance and education. 
Like Krug, Levine argues that children should be schooled in media literacy and moral intelligence rather than be exposed to censored versions of the Internet: "... to give children a fighting chance in navigating the sexual worlds, adults need to saturate it with accurate, realistic information and abundant, varied images of love and sex." Educational programs towards Internet literacy and sexual politics in high schools and higher education would be needed to close the gap between top-down government measures and decentralized online communities.

\section{Online Porn Journeys}

While cyberculture theorists have investigated the erotic bind of web-based communication for more than a decade, governments decline to investigate new communication methods as a way to approximate responses to the porn boom. Electronic networks continue to feed the porn boom and facilitate new methods for

consumers to interact with porn. With a shift in porn consumption comes a new way of thinking about sexuality, as net users of different backgrounds start networking in their search for partners and porn.

Rana Dasgupa in "Sexworks/Networks: What do People get Out of Internet Porn?" argues that porn browsing aims at closing the gap between the desiring body and the dispersed organs of sight, hearing and information processing. This dream has come to fruition with the development of cybersex communication and online databases, where users practise social rules, ethical codes and fantasies that are openly articulated yet potentialy obscure to the outside world. Dasgupta believes that a mental and bodily attachment of net users to communication can no longer be separated from porn consumption habits: "In actual fact, the market exists in great part because of the intense libidinal attachment it cultivates in consumers. It cannot be selective as to which parts of that attachment it will acknowledge as its own creation" (Dasgupta: 2002). Online correspondents are multi-taskers who move between activities such as socializing, buying commodities and searching information. Following Arjun Appadurai's definition of mediascapes, porn geographies can be imagined as amorphous spaces, 
where consumers may link to diverse sites and are able to apply forms of agency such as resistance, irony and selectivity. Consumer agency is a crucial component to the life of mediascapes as it opens a space for the imagination and enriching cross-cultural encounters (Appadurai, 1996: 35).

Governments and cultural establishment are slow or unwilling to investigate the effects of mediascapes on porn consumers, their codes of ethics and movement towards decentralized communication, role-play and free speech. This is no surprise to the history of pornographic media. Two studies on the origins of pornography in modern culture, Walter Kendrick's The Secret Museum: Pornography in Modern Culture (1996), and Lynn Hunt's The Invention of Pornography: Obscenity and the Origins of Modernity, 15001800 (1997), show that attempts to restrict the distribution of porn have historically been part of a larger objective to limit access to public spaces. Porn emerged within male elite groups, or "male domains," who thoroughly feared the democratization of culture and protected secret collections from the lower classes and women's communities.

Over the last few decades, porn has undergone a shift towards decentralization and heterogeneity, as a wider variety of producers and consumers participate in the making of globalized markets. A contemporary notion of porn should capture such networked sexual agency and politics. This view would in accordance with a sexually exuberant climate, as small places such as homes, bedrooms or cybercafes become sites for networked activity (Duncan, 1996: 136-137). Rather than viewing home-spaces as distinctly contained spaces, or sites of "patriarchal" or "matriarchal" domination, home spaces can be seen as networked nodes where individuals negotiate complex social and ethical codes. The ability to seek out and share sexual practice in response to online commodities and communities arguably creates new public freedoms. ${ }^{1}$

An insightful theoretical model could be Foucault's early definition of space as "heterotopia". In his essay "Of Other Spaces,"(1986, originally published in 1967). Foucault purports that we live in an epoch of space, where space is not a delineated entity but one which constantly fragments and dissolves, reforming as other spaces. With modernity, the medieval concept of space as emplacement is replaced by that of "heterotopia", a disembodied notion of space whose fixed nature and location is 
constantly disrupted by transience and ever-shifting relations between places. Foucault was particularly interested in spaces that are linked to 'other' sites and which differ from the sites they reflect and speak about. According to Foucault, heterotopias are capable of taking several sites which are incompatible or "foreign to one another" and juxtaposing them within a single space (25). Similarly, online consumers practice a pluralistic moral consciousness as they endlessly move between sites and/or long to visit other spaces. Sex sites are effectively linked to "other" sites, encouraging consumers to satisfy diverse urges and move between activities such as shopping, chatting, peeping, cruising, masturbating, maintaining friendships. Foucault uses the example of festivals and fairgrounds, but one could also make examples of porn spaces as consumers mix and match diverse cultures and types of agency. ${ }^{7}$ Daniel Defert explains that Foucault's concept of space meant to introduce a carnivalesque order of existence:

These spatio-temporal units, these space-times, shared the fact of being places where I am and yet I am not, as in the mirror or the cemetery, or where I am another, as in the brothel, the vacation resort, or the festival: carnival transformations of ordinary existence, which ritualize splits, thresholds, and deviations, and localize them as well.

(Defert, 1997: 275)

"Heterotopia" is Foucault's characterization of disorder and chaos in spatio-temporal units, and how they enabled intricate and multiple, often conflicting, workings of thought and gestures. Heterotopia was first defined by Foucault as "a disorder in which fragments of large number of possible orders glitter" (Defert, 1997: 275).

Foucault is perhaps a foreteller of cyberspace in sketching ephemeral and disorderly communication, though a newer reading of his concept would include the disorder of bodies and spaces of actual correspondents. Porn heterotopias cannot be seen as purely disembodied spaces, but rather as mediated spaces where porn users explore phenomena and intersect with each other's mental, physical and emotional journeys. In order to discuss porn browsing as "journeying", one could make use of Michel de 
Certeau's concept of "space," which he contrasts to the concept of "place". Whereas places are distinct locations and imply an indication of stability, spaces are constituted through movements and operations of bodies and minds: "Space occurs as the effect produced by the operations that orient it, situate it, temporalize it, and make it function in a polyvalent unity of conflictual programs or contractual proximities "(Roberson, 2001: 90). We are "spacing" when we explore operations of contact, its waves and obstacles, changing methods of communication, the home-spaces we occupy, the cultures we visit, the fantasy-spaces we construct around journeys. De Certeau's "spacing" allows us to conceptualize complex attachments and reflect on networked agency.

Web-based artists and writers such as Francesca da Rimini have equally commented on sex journeys and concepts of space. ${ }^{8}$ Da Rimini's site documents a libidinal search for love as "journeying," showing how contacts and fantasies are built, expanded, ruined, refurbished over time. The site demonstrates web life as journeys into multiple bodies. Da Rimini took on libidinal identities to develop fluid concepts of space. "Spacing" is established through her fictions, e.g. the character "doll yoko," a character who "...swims up from a crater mud pond of dead girls as her pale hands perform gentle inquisitions upon your fleshform as she haunts your imagination." Doll yoko is a character rooted in Japanese folklore, exotic fetishism and da Rimini's personal memories. Da Rimini invented doll yoko in a small place near Kyoto, a place where she was on holiday and where according to local legends, Japanese baby-girls had been drowned at birth. The legend of this place entered doll yoko's journey and linked her to other characters such as "gashgirl," a cynical vampire who rips into fleshforms, or the dominant and self-absorbed "puppet mistress" who sees the web as a "global freak show". Da Rimini explains that these alter-ego personas had a profound impact on her own everyday body and sexuality:

During the 3-4 years that I was most intensely reconfiguring myself as an online erotic intelligence, as GashGirl and later as doll yoko, a period of my life that was particularly marked by obsession, an addictive relationship to going online, 
euphoria, wild oscillations of emotions, relentless creative output, I was experiencing my body in new ways, far more sexualized, responsive to suggestion and physically sensitive than it had been before. This went hand in hand with a driving need to write, to write daily, hourly, to never leave the screen, to record the psychic and emotional development of the characters I was inhabiting, and the passages of the relationships they were forming with other minds played out within the liquid space of the nets. ${ }^{9}$

Online correspondences dissolve the borders between small places and other spaces, enabling complex relationships between remote agents to emerge.

\section{Pornography and the Gift}

Online porn is consumed in spaces where remote partners communicate and social or moral agency merges through conversation, sex or pornographic commodities. Pornographic agency as "journeying" relies on a specific type of performativity, community networking, as well as interconnectivity and access. In her essay, "Distributed and Hierarchical Power," Saskia Sassen (1998) argues that online correspondents hold a peculiar type of non-hierarchical power that is disruptive to national governments. Even though Sassen's research views corporate sites as the main invaders of web space, she believes that forms of Internet activism destabilize hierarchical power structures materialized by nation-state governments and corporations.

In Time and Commodity Culture (1997) John Frow posits gift exchange as a way to think late capitalism's commodity culture. Gift exchange supplements commodity exchange in that it aims to construct a mechanism of social cohesion rather than economic utility or profit. Frow's theory of the gift borrows insights from Georges Bataille, Jacques Derrida and Annette Weiner's anthropological study on 'inalienable' possessions in Oceanion and Aboriginal Australian cultures. Weiner's study of the gift shows that inalienable possessions go beyond a law of reciprocity, as they are the object 
of most intense desire (Frow, 1997: 129). In Maori cultures, for instance, women's production of cloth becomes uniquely important because it is imbued with a procreative power and requires a specific type of guardianship which turns difference into rank (Weiner, 1992: 18).

Theorists have started to investigate how web users use the Internet to construct alternative types of exchange to consumerism. The mailing list Nettime has had extensive discussions on gift economies destabilizing the objectives of consumerist capitalism. As Keith Hart argues:

Even if the Internet is a creature of capitalism, there have always been strategies for ordinary people to claw back something of the value of what they produce. When such practices are identified as "the informal economy" (again a misleading expression, if it implies the absence of dialectical relations to the dominant forms), we can only note that what was taken in the 70s to be an insignificant sector of the total economy is today recognised to be very large in scope at all levels including the global. So it is possible for practices which are objectively minor to provide a site in which alternatives to the currently dominant economic form are developed. 10

Porn users transfer personal information alongside pornographic commodities as they share and distribute sexuality. Such exchanges may become part of web users "special collection" even though commodities are still available to a wider market economy through the Internet. When consumers withdraw products from "pure" market relations and reserve them for other purposes, the logic of the commodity form becomes, in Frow's suggestion, enabling and productive instead of limiting and destructive.

Frow's analysis is inspired by the ideas of Georges Bataille, who in The Accursed Share. Volume 1: Consumption questions how the determination of excess energy circulating in the biosphere is altered by human activity. He juxtaposes secular economy with general economy, postulating that the latter has less restrictive ways of channeling or utilizing excess energy. Whereas modern economies are founded on a pietist moral 
code which condemns idleness and luxury and affirms the value of enterprise, general economy is based on the notion of excessive gift which can only be consumed in a different manner. The gift enhances a performed consumerism and leads to a process of self-consciousness, or ritualized enactment of a culture's high point of exuberance, ecstacy, or intensity. Such awareness of a culture's "accursed share" is absent in capitalist economies that channel excessive energy by other means, such as war.

In capitalist societies, full membership of the public has traditionally been tied to the ability to partake in commodity exchange. To refuse to partake in such a system is to forego the status that comes with citizenship. In pre-capitalist societies, other types of exchange secured forms of social cohesion between individuals. It is important in this context to note that many pornographic encounters on the Internet revolve around offers of commodities, gifts, or "teasers" to Internet consumers. It was reported in May 2002 that the golden age of online porn-trade was going in decline, precisely because it would be harder for businesses to convert viewers into subscribers ( $\mathrm{O}^{\prime}$ Brien, 2002). The Internet has created porn markets as well as a 'general economy' where different forms of economic exchange are practiced.

An example of porn consumers "clawing back" from consumerist activities would be women's communities sharing and modifying Japanese "dolls" or popular pornographic cartoon characters. A peculiar "doll" network has emerged through the World KiSS Project, a project which attracts web users in both Japan and internationally to explore the viral life of commodity forms by exchanging transformed versions of the dolls. As Anne-Marie Schleiner (2000) observes: “The process of creativity employed by KiSS artists is a form of cultural sampling, hacking, and appropriation, a form of play from which new configurations emerge". Schleiner adds that the international responses to World Kiss are creating an interactive culture open to fantasies that deviate from the sexual norms: "As an open source strip doll player, the World KiSS Project allows its users to insert their own erotic fantasies into the mix rather than relying on a particular industry to feed its users prepackaged sexiness [...]allowing queer, hetero, femalefriendly, fetish, Goth, Japanese bondage, anime tingles, $[\ldots]$ and other fantasies to be distributed and exchanged". 
Cross-cultural romance and gift-giving are vital operations established between web users. Francesca da Rimini, for instance, often exchanges products (writings, images) with correspondents willing to enter her "free trade" zone and write out their fantasies. As she explains:

From the outset I was blown away by the trust and the commitment to the game, the contract, the obligations, that my playmates offered me. The gift was theirs, and also mine, it was a field of reciprocal exchange, a free trade zone. I felt free to use the gifts I had been given as source material for both my book FleshMeat, and online projects such as 'dollspace' and 'princess valium'. The contracts I established with my playmates allowed me to use transcripts of our correspondences and online interactions in whichever way I chose, and it was understood that I had an editorial power, but not the right to alter their words. I had no interest in making a direct financial profit from these gifts, it wasn't part of the deal. ${ }^{11}$

A number of porn producers have started to build independent websites to have control over the exchange with their clients and create community-friendly commodity environment. Nakkidnerds.com, maintained by Cloei, a 24 year old woman from Cambridge, Massachusetts, is a web-based network requiring paid membership. Cloei describes herself as "a shy woman who has a fetish for nerds". Cloei first worked as a model for commercial porn sites and then started to build her own company and web communities. Nakkidnerds.com encourages "nerdy" girls such as web designers and art students to showcase their bodies and to communicate with viewers through chatrooms and messageboards. Cloei created the company in order to give a more versatile picture of porn stars and set up a less exploitative network and work ethic for camgirls. As she writes in her homepage greeting:

I am sick and tired of searching through the net looking at page after page of tall blonde cookie cutter girls that you KNOW are NOT true amateurs. These days searching for "adult material" is just site after site of the same girls with a few 
rare exceptions, and frankly it is giving us wild web chicks a bad name. And that's not fair now is it. So I decided to do something about it. I wanted to capture the girl you see in the back of the class sitting there reading her book not paying attention to anybody. The girl you see on the street walking to work, or the girl who sits in the cube next to you day in/day out coding her little heart out. Girls who have much more than a pretty smile to offer, but also an amazing mind $(\ldots)^{12}$

Cloei was one of the first camgirls to gain national acclaim among the webcam community. Her site is an immediate departure from commercial porn in that she does not hire professional models but generally works with amateur-models, friends and acquaintances. In an area called "geekgurls", Cloei introduces her models and what kind of relationships she has with each of them. Viewers are encouraged to interact with the network and comment on issues through chat rooms and message boards. They can either talk to girls who are online, or post questions and ideas about sexuality in an online forum.

Www.ssspread.com, a site set up by Barbara DeGenevieve from the School of the Art Institute of Chicago, wants to "serve the queer community with a kind of pornography that is underrepresented on the $\mathrm{web}^{\prime \prime}$. The collective intends to make the porn site "an exception to every rule" by making it "truly interactive". Just like nakkidnerd.coms, ssspread.com is a pay-site where members get access to images through a monthly membership. On May 10, a story called "the plumber" showed a domestic housewife being seduced and fucked by a transgender plumber. The ssspread community gives feedback to the stories by writing messages on a messageboard. Ssspread.com works with non-professional models who are happy to be showcased, are paid a nominal amount of money for each film shoot and do not necessarily conform to beauty norms. Ssspread.com also builds community by giving out members information so that they may be able to contact each other. The site contains links to pornographic stories in the "Story Lounge" area. The "Articles and Interviews" area contains interviews with activist pornographers and scholars such as Shannon Bell and Annie Sprinkle. 
Maria Beatty is a lesbian fetish and s/m porn producer who in 1997 founded Bleuproductions.com, an online video distribution site. Beatty set out to introduce a new type of "playfulness and eroticism" in her videos, presenting lesbian $\mathrm{s} / \mathrm{m}$ in a more "elegant, sensual, feminine film style", as she felt that the adult video market was still too much 'focused on easy, gratuitous and or blatant, raw sex-scenes ${ }^{\prime 13}$. Beatty believes that independent producers benefit from Internet distribution as it enables them to sell works at retail value, have more control over publicity, and easy access to international consumers and distributors.

Beatty's debut film The Elegant Spanking (1996) was initially primarily shown at lesbian and gay film festivals, both domestic and international, and to a limited wholesale market through the distributor Outspoken Productions. Now that The Elegant Spanking is distributed through Bleuproductions, sales have quadrupled, and audiences have come to include male and female heterosexual viewers. While Beatty was primarily categorized as a "lesbian filmmaker" catering to queer communities in the independent festival circuit, she is now considered to be an "underground classic art filmmaker", and has started to cater her movies to mixed gay/lesbian and straight audiences. Even though her most popular videos, The Sassy Schoolgirl (an underage looking schoolgirl and female schoolteacher who role-play corporal punishment, 1998), The Boiler Room (a very explicit lesbian s/m video with enema and cavity exploration, 1999), and Doctor's Orders (nurse-patient medical scenarios, 1999) cater to 'mainstream' fantasies, fetishes and demands, Bleuproductions has enabled Beatty to work independently and work out a more personal and experimental film style.

Moreover, through her website and email correspondences, Beatty receives feedback to her videos from consumers across the world. She believes that Internet distribution allows citizens from more restrictive countries to buy tapes from off-shore producers and engage in correspondences.

\section{Porn and Queer Markets}


Consumers are "spacing" or traveling between sites, actual and virtual places, multitasking activities and altering the goals of pornography. In all of the discussed porn sites, a new type of economy is being constituted around the commodity exchange between pornographers and their consumers. How can we view such renewed definition of porn consumption in light of capitalism's tendency to control ownership, consolidate content and maintain class divisions between cultures? It has become clear over the last years that the World Wide Web has lost its original narrower function of information-sharing and free-speech community. Studies such as Wyatt, Henwood and Senker eds. (2000) Technology and In/Equality: Questioning the Information Society, and Kolko, Nakamura and Rodman, eds. (2000) Race in Cyberspace show that cyberspace as a newly coded environment reproduces inequal conditions for access and participation.

One web site that has traditionally helped to legitimate gay and lesbian porn is the activist site Popcorn $Q .{ }^{14}$ Even though Popcorn $Q$ is rooted in efforts at free communication and lesbian/gay activism, the formation of community politics happens alongside commodity exchange such as the consumption of movies and products. The site recently merged with a much larger lesbian/gay site, Planetout.com, which in its own time merged with Gay.com. While the early producers of PopcornQ invited local communities to order movies and create sites of local entertainment and activism, Planetout.com and Gay.com clearly target "world-wide" sexual communities as consumers of products and services. As CEO Lowell Selvin of Online Partners, the parent company of Gay.com, explained in a press release that announced the Gay.com and PlanetOut merger:"The gay and lesbian community will be the winner in this merger because, for the first time, the LGBT market becomes a true economic force. Never before could any organization bring together this many gays and lesbians to command the attention of businesses worldwide. This merger will create a company that reaches more than 3.5 million people around the world each month and that combined reach is sure to attract even more leading mainstream advertisers and business partners." ${ }^{15}$

Megan Smith, CEO of PlanetOut explains that the merger will serve a "diversity" of global gay and lesbian communities: "With the two largest brands under one umbrella, we can aggregate resources and serve our customers even more effectively, providing 
the range of media, community, entertainment, products and services that reflects and addresses the diversity of LGBT people. ${ }^{\prime 16}$ PlanetOut.com functions as a portal that brings together a comprehensive set of areas for e-commerce, chatrooms, horoscopes, health news, and the everyday news. Thomas and Wyatt in Technology and In/Equality: Questioning the Information Society criticize the portal model for pampering rather than educating consumers: "The portal model, and the heavy presence of traditional media organisations, gives impetus to the idea of 'pushing' content - including advertising - at customers rather than waiting for them to pull it down"(Wyatt, 2000: 37). They explain that the portal model is an important stage in streamlining Internet content so as to emphasize its commercial function. They believe that the portal model exacerbates the 'digital divide' between web users, based on national-origin, race and gender. In the case of Planetout.Com, we may assume that a consolidation of gay and lesbian media will increasingly enable individuals and communities globally to access gay and lesbian media and commodity exchange, and participate in sex forums at the margins of commodity exchange.

\section{Conclusion}

The future of pornography's speech is at stake since online consumers are increasingly moderated by stricter agreements between nation-state governments and globalized industries. Queer politics may be transformed and/or hampered by the draw of more aggressive and visible commercial porn networks. Frederick Lane (2000) believes that porn consolidation goes hand in hand with visions of corporate ownership and technological determinism: 'The Internet corollary of a tony address, vast distribution networks, and economy of scale will be the ability to engage in ubiquitous advertising and to develop and implement the latest technological improvements" (Lane: 2000, 235). Porn's 'tony address' may become a necessary evil in our erotic marriage with the Web, causing stronger reactions in mainstream populations and governments. This article shows that despite current porn and sex wars, the Internet creates consumers who are eager to operate the viewing contexts of porn spaces. Porn consumers are citizens of 
heterotopia engaged in multiple lines of communication. Sexual adventures and amateur porn exchanges create liberal social and ethical codes alongside the profit-oriented goals of the porn industry. Using theories of space and the gift, the article envisions cyberspace as amorphous spaces and bodies willing to consume porn alongside nonmainstream communities and activism.

1 The Frontline American Porn site is located at http: //www.pbs .org/wgbh/pages/frontline/shows/porn/interviews/ash er.html

2 The Internet Watch Foundation site is located at http: //www.iwt.org.uk

3 For more detailed information on the visto terms of agreements (TOS) see http://www.visto.com

4 Information gathered from diverse anonymous sources, correspondences between moderators and members of porn sites hosted by Egroups and Visto In a paper delivered at the 2003 Society for Cinema and Media Studies Conferecne, 'Making Brad and Ryan Heterosexual Again: The Struggle Between Gay Fans and the Hollywood Machine to Control star Discourse, Male Bodies and Gossip on the Web,' Ronald Gregg explores how the Web recently challenged Hollywood's control of star discourse by allowing gay fans, for instance, to post illicit gossip, pornographic images and homoerotic fantasies concerning male stars that were as accessible as official star websites. Hollywood's efforts to rein in this unauthorized star discourse helped fuel recent efforts to regulate web content.

5 The Western Australian Censorship Act of 1996 stipulates that within any of those communication technologies, 'objectionable' articles are those that 'contain child pornography, or depict in an offensive manner crime, violence, torture and pornographic imagery such as necrophilia, sadomasochism, golden showers, and bestiality.' (Western Australian Censorship Act, 1996)

6 For a good discussion of censorship and Internet filters, see Judith Levine, Harmful to Minors: The Perils of Protecting Children from Sex (University of Minnesota Press, 2002: 15-17).

7 Ibidem. 
8 The online writings of Francesca da Rimini are located at http://sysx.org/gashgirl/arc/index.html

9 Personal interview with Francesca da Rimini, August 4, 2000.

10 Keith Hart, Posted by Phil Graham, 13 Jan 2000, Subject <nettime> Post re: "the gift"

11 Personal interview with Francesca da Rimini, August 4, 2000.

12 Cloei's website is located at http://www, nakkidnerd.com

13 Personal interview with Maria Beatty, February 19, 2000.

14 Popcorno is a San Francisco-based network which has sponsors gay and lesbian filmmaking internationally for more than a decade $^{14}$ Popcorno first functioned as the addendum to a book publication, The Ultimate Guide to Lesbian and Gay Film and Video (1996), a comprehensive anthology of gay and lesbian films and videos, including porn and erotica, with descriptions, pictures and distribution information. The book also explained in a stepby-step approach how to organize a film screening and create a unique program around audience, genre, sexual orientation, or taste.

15 http://www.planetout.com press release, Gay.com and Planetout plan Merger, posted november 11, 2000, downloaded, May 22001 .

16 Ibidem

Websites

Francesca da Rimini http://sysx.org/gashqirl/arc.index.html

Maria Beatty http://www.bleuproductions.com

'Cloei' http://www, nakkidnerd.com

Spread Community http://www.ssspread.com

\section{$\underline{\text { References }}$}

Appadurai, Arjun (1996) Modernity at large: Cutural Dimensions of Gobalization. Minneapolis: University of Minnesota Press. 
Barlow, John Perry (2000)'Censorship 2000'. Posted on Internet mailinglist <Nettime>, July 12 2000, http://www.nettime.org.

Bataille, Georges (1991) The Accursed Share. Volume 1: Consumption, New York: Zone Books.

Butler, Judith (1993) Bodies That Matter. On the Discursive Limits of Sex. London: Routledge.

Cheah Peng, David Fraser and Judith Gerbich (eds) (1996) Thinking Through the Body of the Law, Sydney: Allen and Unwin.

Daniel Defert (1997) 'Foucault, Space, and the Architects'. Politics/Poetics. Documenta $x$-The Book (Ostfildern-Ruitz:

Cantz Verlag), p. 275 .

Dasgupta, Rana 'Sexworks/Networks: What do People Get Out of Internet Porn?,' http://www.sarai.net, downloaded May 6, 2002

Diprose, Rosalyn (1994) The Bodies of Women: Ethics, Embodiment and Sexual Difference. London: Routledge.

Duncan, Nancy (1996) Body Space. London: Routledge

Felski, Rita (1995) 'Imagined Pleasures: The Erotics and Aesthetics of Consumption'. In her The Gender of Modernity (Belknap Press) 61-91.

Foucault, Michel (1986) 'Of Other Spaces', Diacritics 16(1), 2227 .

Frontline program 'American Porn,' http://www.pbs.org/wqbh/pages/frontline/shows/porn/interviews/ash er.html, downloaded May 5, 2002 .

Frow, John (1997) Time and Commodity Exchange. Oxford: Clarendon Press.

Hunt, Lynn (1997)The Invention of Pornography: Obscenity and the Origins of Modernity. 1500-1800 (M.I.T. Zone Books)

Kendrick, Walter (1996) The Secret Museum: Pornography in Modern Culture University of California Press.

Lane, Frederick S. (2000) Obscene Profits. The Enterpreneurs of Pornography in the Cyber Age. New York: Routledge. 
Lessig, Lawrence (1999) Code and Other Laws of Cyberspace, New York: Perseus Books.

Loviglio, Joan (2002) 'Librarians Resist Filtering Technology to Block Adult Sites, The Boston Globe, March 25.

Lumby, Catherine (1997) 'Panick Attacks: Old Fears in a New Media Area', Media International Australia'. 85 (November), 4047 .

Mc Quire, Scott (1999)'Electrical Storms: High Speed

Historiography in the VideoArt of Peter Callas'. In Peter Callas:

Initialising History Sydney: Dlux..

McLelland, Mark (2000) 'No Climax, No Point, No Meaning? Japanese Women's Boy-Love Sites on the Internet' Journal of Commercial Inquiry: 24.3 .

(2001) 'Out and About on the Japanese Gay Net'. In Mobile Cultures: New Media and Queer Asia. Duke University Press (Forthcoming)

Olson, Jenni (ed.) (1996) The Ultimate Guide to Lesbian and Gay Video. New York: Serpent's Tail http://ww. planetout.com. popcornq

O'Brien, 'Boom Times Have Passed for Online Porn,' Siliconvalley.com, Posted May 4 2002. Downloaded August 62002 .

O'Toole, Lawrence (1998) Pornocopia: Porn, Sex, Technology and Desire. London, Serpent's Tail, 1998.

Plant, Sadie (1992) The Most Radical Gesture. London: Routledge

Roberson, Susan ed. (2001) Defining Travel: Diverse Visions. Jackson: University Press of Mississippi

Sassen, Saskia, Lecture at the conference Kino-Eye: Cybercities, Antwerp, 20-22 November 1998 .

Schleiner, Anne-Marie (2000) 'Open Source Art Experiments: Lucky Kiss'. Nettime, November 26, 2000.

Soja, Edward W. (1996) Thirdspace: Journeys to Los Angeles and Other Real and Imagined Places. Oxford: Blackwell. 
Supreme Court Debates, 'Internet Pornography,' February 2002.

Weiner, Annette B (1992) Inalienable Possessions: The Paradox of Keeping While Giving. Berkeley: University of California Press.

Wyatt, Sally, Flis Henwood, Nod Miller and Peter Senker eds.(2000), Technology and In/Equality: Questioning the Information Society. London: Routledge. 